\title{
Tras la bruma. Megalitos, difusión y conservación en el noroeste de España
}

Fernando Carrera Ramírez, Escola Superior de Conservación Restauración Bens Culturais de Galicia

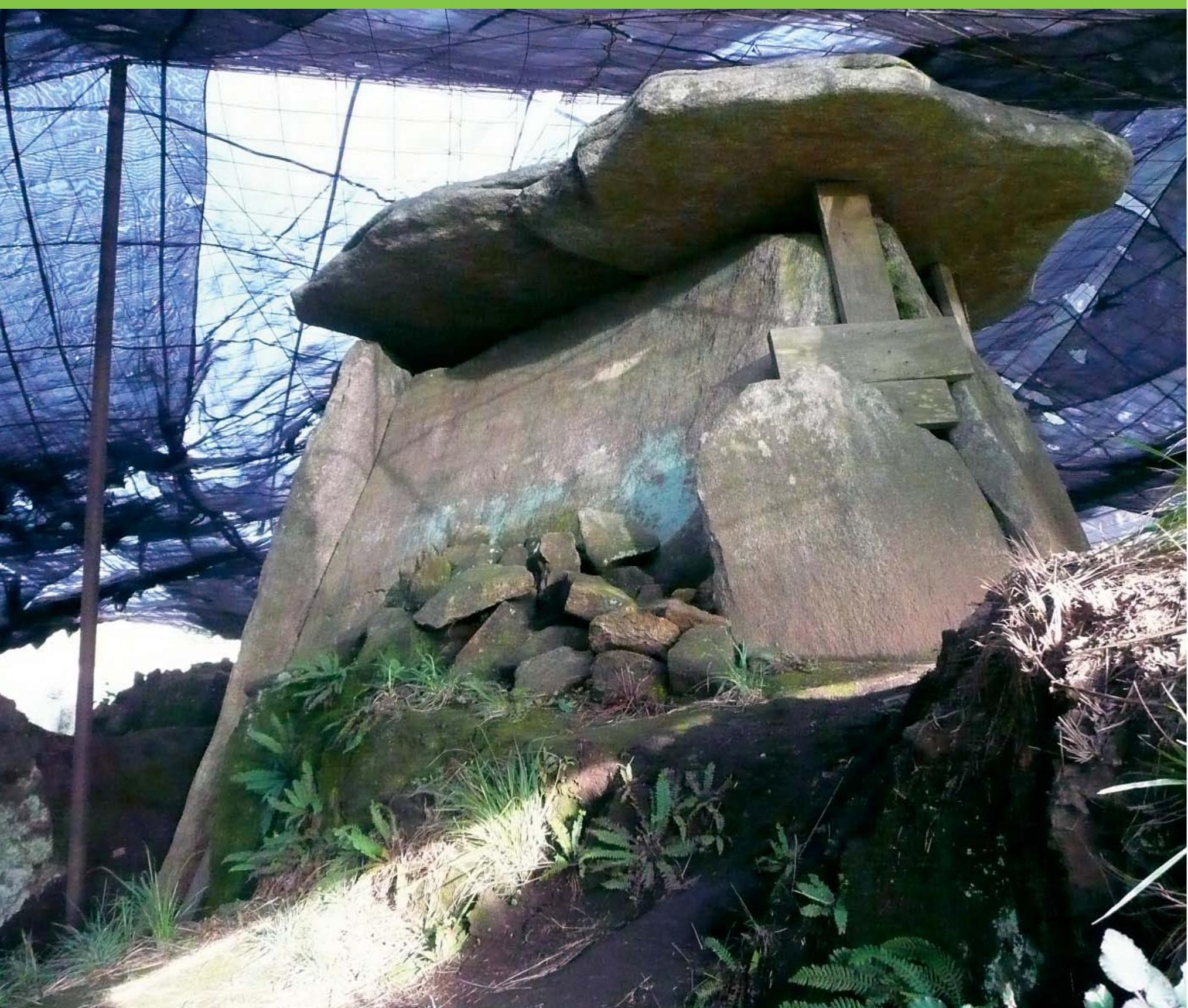




\section{Resumen}

En el presente artículo se describe de forma somera el estado del conjunto patrimonial conformado por los monumentos megalíticos del noroeste de la Península Ibérica. A continuación, se han estudiado los yacimientos que muestran algún tratamiento destinado a su pública exhibición. Finalmente, partiendo de una valoración negativa de todo lo anterior, se formulan estrategias para lograr la paralela exhibición y conservación de un grupo de yacimientos megalíticos gallegos.

\section{Palabras clave}

Arqueología I Conservación I Galicia I Gestión I Megalitismo I Patrimonio arqueológico I Península Ibérica I Portugal I

Protección del Patrimonio Histórico I Zona noroccidental

\section{PATRIMONIO, DIVERSIDAD Y RUINA}

Pese a su nombre, el patrimonio megalítico no está formado exclusivamente por monumentales arquitecturas pétreas. Para nuestra fortuna, y aunque esto no tiene una formulación legal ni siquiera científica precisa, bajo ese término encuadramos túmulos, corazas y arquitecturas no megalíticas; elementos escultóricos, arte parietal y una diversidad de elementos culturales que conforman un corpus ritual cada vez más poliédrico. En sus respectivas imperfecciones, quizá fuera más preciso hablar de patrimonio neolítico inmueble, patrimonio tumular o incluso de patrimonio funerario neolítico, entre otros posibles. Dejemos pues los nombres dado que nos vamos entendiendo razonablemente, pero vayamos integrando en el conjunto del patrimonio megalítico aquellas formas menos rotundas pero igualmente relevantes. Esa visión permitirá que fijemos la atención sobre elementos con frecuencia desatendidos cuando se discute de conservación o exhibición de ese grupo patrimonial.

Enlazando con lo anterior, quizá convenga aclarar al lector que al autor le preocupan más las acciones de conservación (y protección, si se quiere) que las más publicitadas intervenciones de musealización o exhibición de algún monumento relevante. No tanto porque no nos parezcan interesantes las acciones tendentes a la difusión sino porque éstas suelen ser las que absorben la totalidad de la atención política, administrativa e incluso técnica. Mientras tanto silenciosamente a nuestra espalda el conjunto del patrimonio (megalítico, en este caso) se sigue degradando de forma irreversible.

Intentando descubrir y documentar los restos de un arte parietal megalítico maltratado y olvidado, en los últimos tiempos hemos venido viajando de forma habitual por los montes de Galicia (CARRERA RAMÍREZ Y FÁBREGAS VALCARCE, 2006) (imagen 2). Pues bien, más allá de las notables y recientes degradaciones observadas en muy afamados dól- 

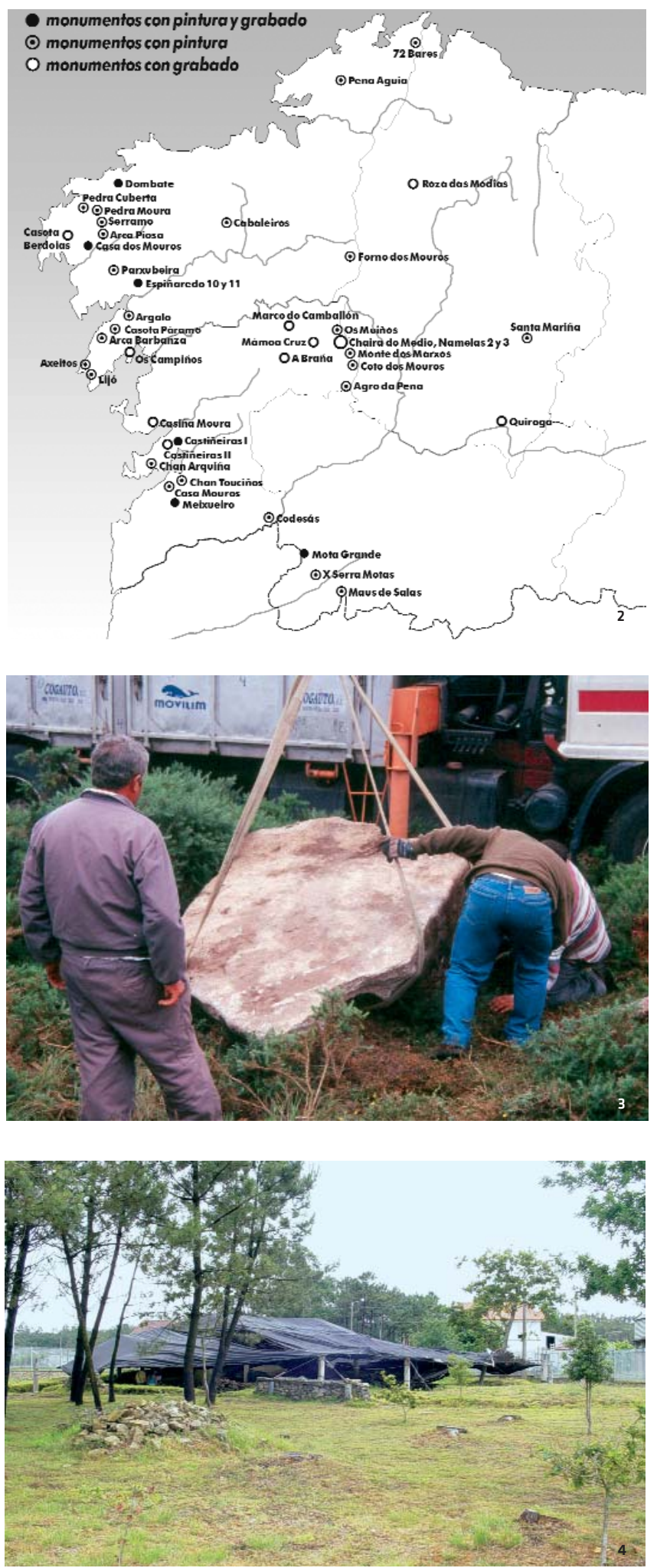

menes, nos ha impresionado especialmente la permanente constatación de destrucciones de túmulos menores, en un proceso que -por repetidoparece haberse convertido en algo a lo que individuos e instituciones nos hemos acostumbrado. Aunque el autor ha conocido algunos casos, sabemos de muchos arqueólogos que podrían citar largas relaciones de monumentos tumulares destruidos en los últimos tiempos.

Y aunque para la reconstrucción histórica el más pequeño túmulo es relevante, nos impresiona especialmente la devastación que asimismo alcanza a monumentos de gran envergadura. Por citar algunos casos, podríamos señalar el muy reciente (año 2000) de un dolmen con pintura megalítica completamente destruido (Monte dos Marxos, Rodeiro, Pontevedra) (imagen 3), o la práctica desaparición en 2001 de la Mámoa do Agro da Pena (Dozón, Pontevedra), asimismo con pintura. Casos semejantes, aunque menos recientes, son las destrucciones de los dólmenes de la Mámoa da Braña das Feallas (Zas, Coruña) en 1994 o A Peneda de Guntín (Frades, Coruña) en 1996. Más suerte han corrido otros monumentos en los que las obras les han afectado sólo parcialmente: las bien conocidas carreteras que cortan Mamoa da Cruz (Lalín, Pontevedra) o Chan de Castiñeiras 2 (Marín, Pontevedra), o el caso reciente de Casota de Berdoias (Vimianzo, C.), donde el asfalto del renovado camino quedó escasamente a $1 \mathrm{~m}$ de la estructura megalítica. El relatorio anterior es muy superficial por la limitación de la selección estudiada (sólo grandes monumentos) y por el corto período de inspección. Precisamente por eso, las alteraciones observadas tienen escasa relevancia estadística pero notable sentido simbólico.

Para frenar esa insoportable pérdida, consideramos que deben ponerse en marcha un conjunto de acciones interrelacionadas de las cuales la musealización de inmuebles es sólo una de las más visibles. Por todo ello hemos hablado repetidamente de un plan general para la protección del patrimonio megalítico (CARRERA RAMÍREZ, 2002). La condición para que se frene la destrucción de ese patrimonio, pero también la consecuencia, es la mejora del reconocimiento y aprecio popular del mismo. Y como paso previo, establecer el volumen y estado del conjunto, información que se empleará tanto en el diseño de las acciones de protección como en la mejora de los mensajes de difusión.

\section{PATRIMONIO MEGALITICO EXHIBIDO EN GALICIA}

Mientras todo aquello acaece, las intervenciones de musealización de dólmenes en Galicia tampoco son (por desgracia) muy frecuentes. Como en otras áreas peninsulares, el esquema habitual es el del dolmen violado de antiguo, parcialmente visible y conocido (y visitado) por un número más o menos reducido de personas, siendo muy pocas las intervenciones integrales en España (APELLÁNIZ CASTROVIEJO; FERNÁNDEZ MEDRA- 
NO, 1978; FUENTE ANDRÉS, 1988) y quizá más abundantes en Portugal (por ejemplo, STOCKLER, 1996). Del limitado conjunto de yacimientos megalíticos visitados en Galicia en los últimos tiempos ${ }^{1}$, hemos observado intervenciones de musealización, conservación o mantenimiento en 17 sitios (tabla 1), resultando revelador que 49 de los visitados no posean intervención alguna, entre los que se cuentan yacimientos muy relevantes en la literatura arqueológica (Arca da Piosa, Casa dos Mouros, Pedra Cuberta o Roza das Modias, entre otros). Por lo que respecta a los yacimientos que sí han recibido alguna actuación, éstas se pueden agrupar en cuatro niveles:

$\rightarrow$ Actuaciones de exhibición compleja: se trata de aquellos casos en los que, como garantía de protección del arte parietal aunque también como parte del proyecto museográfico se ha optado por colocar una cubierta sobre el monumento (Dombate: BELLO DIÉGUEZ et al., 1997) (imagen 4) o incluso reconstruirlo (Chan de Castiñeiras 1: CASTRO; VÁZQUEZ, 2007). Ambas actuaciones están en ejecución y no puede ser por el momento valorado su interés y efectividad.

$\rightarrow$ Actuaciones de exhibición simple: se trata de monumentos en los que se han ejecutado acciones diversas de cara a su pública exhibición (erección de ortostatos, limpieza, señalización, accesos, etc.), apreciándose un razonable grado de mantenimiento de las intervenciones realizadas. Este sería el caso de monumentos como Axeitos, Cabaleiros, Chan de Arquiña (SOBRINO BUHIGAS, 1956), Casa dos Mouros (Vigo), Outeiro de Cavaladre 1 y 5 (EGUILETA FRANCO, 1999), Mámoa do Rei, y Argalo. Es evidente que existen grados muy diversos tanto en el nivel de intervención como en el de mantenimiento, pero en general muestran estados aceptables de conservación. Sin embargo, en la mayoría de los casos no se garantiza la conservación de la pintura megalítica (en el caso de que la posean: Axeitos, Cabaleiros, Argalo, Casa dos Mouros, etc.), estando expuesta tanto a los agentes atmosféricos (lluvia) como a las acciones antrópicas

$\rightarrow$ Actuaciones no consolidadas: En algunos casos se ejecutaron, al finalizar los proyectos de excavación, escuetas acciones de exhibición (recolocación de ortostatos, limpiezas, etc.) que quizá deberían haberse completado con otras más complejas sin embargo nunca realizadas: es el caso de Os Campiños (FUENTE ANDRÉS, 1988), Parxubeira (RODRÍGUEZ CASAL, 1988) o Chan de Armada. Este tipo de intervenciones apenas parecen haber atraído la atención de las autoridades y carecen de tratamiento alguno de mantenimiento, consecuencia de lo cual muestran estados de abandono ocasionalmente graves (Chan de Armada, Os Campiños) (imagen 5).

$\rightarrow$ Acciones provisionales: Por último, algunas de las intervenciones efectuadas difícilmente alcanzan el calificativo de acciones de exhibición, y más bien parecen meras actuaciones de protección provisional pendientes de un proyecto definitivo. Este parece ser el caso de las acciones emprendidas en Forno dos Mouros (CARRERA RAMÍREZ; BARBI, 1995),

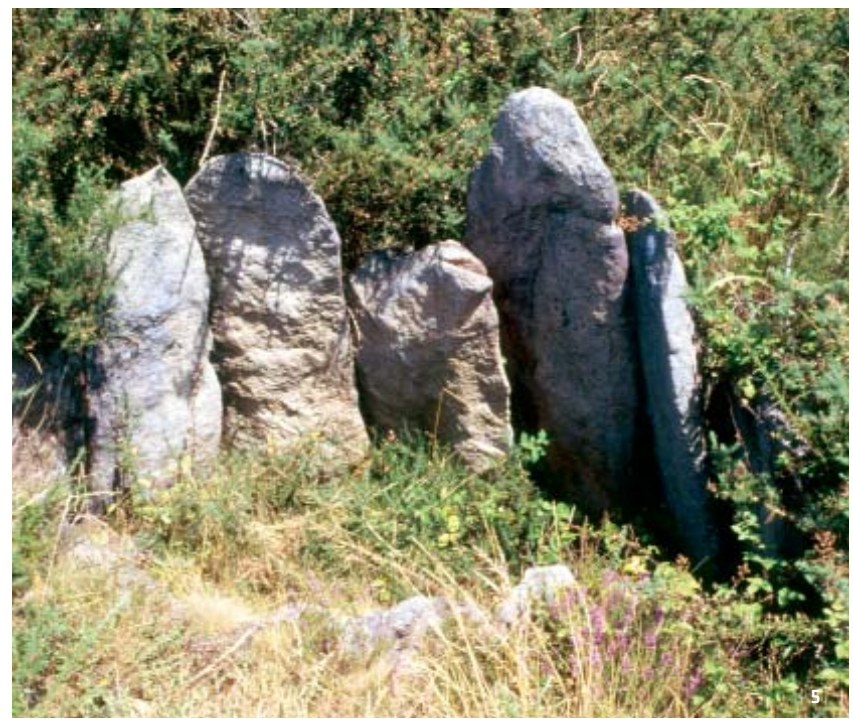

\begin{tabular}{|c|c|c|}
\hline YACIMIENTO & FECHA & DESCRIPCIÓN TRABAJOS \\
\hline Cabaleiros & 1982 & Valla delimitación, cartel y limpieza/roza \\
\hline Pedra da Arca & $i ?$ & Limpieza, cartel \\
\hline Parxubeira & 1982 & $\begin{array}{l}\text { Excavación y tapado. Erección de la losa de cabecera } \\
(C-4)\end{array}$ \\
\hline Argalo & $\begin{array}{l}1980 \\
2004\end{array}$ & $\begin{array}{l}\text { Excavación sin tapado, erección C2 } \\
\text { Reexcavación, limpieza, relleno parcial }\end{array}$ \\
\hline Forno dos Mouros & 1989 & $\begin{array}{l}\text { Acciones preventivas: cubierta de madera y vigas de } \\
\text { hierro }\end{array}$ \\
\hline Chan de Castiñeiras 1 & 2001 a 2003 & Excavación, reconstrucción y musealización \\
\hline Chan de Armada & ¿1978? & Excavación y colocación cubierta \\
\hline \multirow[t]{2}{*}{ Chan de Arquiña } & 1953 & $\begin{array}{l}\text { Excavación y reconstrucción del monumento: } \\
\text { erección de } \subset 4 \text { y } \subset 6 \text {, réplica de } C 5 \text { y tapa de la } \\
\text { cámara }\end{array}$ \\
\hline & 1999 & $\begin{array}{l}\text { Reexcavación y recolocación ortostatos corredor, } \\
\text { tapado pintura }\end{array}$ \\
\hline Costa Freiría & 2007 & Reexcavación y señalización \\
\hline Casa dos Mouros (Vigo) & 2000 & Cartel señalizador y limpieza vegetación \\
\hline Mámoa do Rei & 2002 & Reexcavación, erección C4 y señalización \\
\hline Outeiro de Cavaladre 1 y 5 & 1999 & $\begin{array}{l}\text { Excavación, apuntalamiento y erección ortostatos, } \\
\text { conservación perfiles, señalización, etc. }\end{array}$ \\
\hline Os Campiños & 1988 & $\begin{array}{l}\text { Erección y réplica de ortostatos, limpieza túmulo, } \\
\text { etc. }\end{array}$ \\
\hline Axeitos & $\begin{array}{l}1982 \\
2003\end{array}$ & $\begin{array}{l}\text { Valla perimetral, cartel y limpieza/roza } \\
\text { Nueva valla, nuevo cartel, previsión centro } \\
\text { interpretación (en ejecución) }\end{array}$ \\
\hline Dombate & 1987 y 55. & $\begin{array}{l}\text { Excavación y cubierta provisional, intervenciones } \\
\text { en pinturas. } \\
\text { En la actualidad, en ejecución musealización }\end{array}$ \\
\hline Anta dos Muiños & 2007 & Tapado con sedimentos \\
\hline Mota Grande & 1994 & Tapado con sedimentos \\
\hline
\end{tabular}



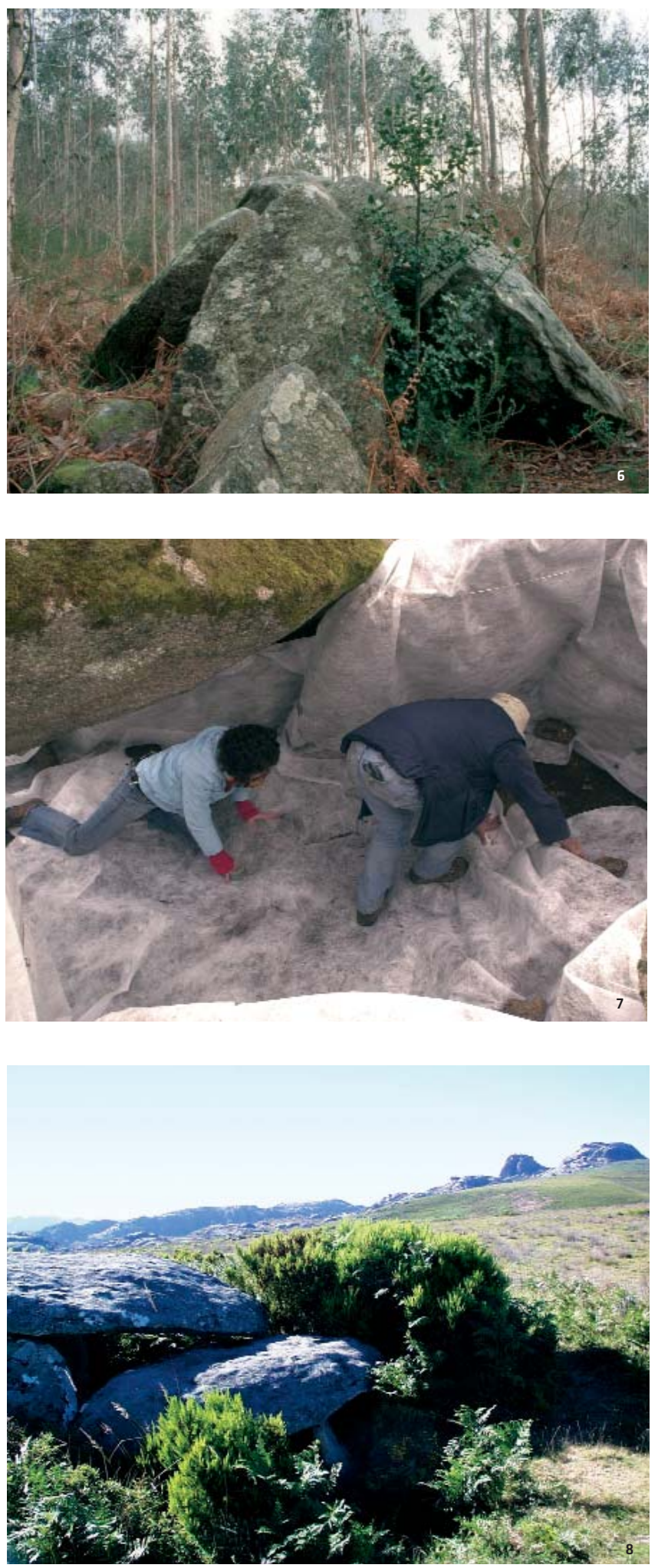

donde las pinturas siguen expuestas a la alteración natural y antrópica. Un caso de protección de la pintura megalítica frente al deterioro lo constituyen los proyectos de re-enterramiento de Mota Grande (CARRERA RAMÍREZ, 1994) o el Dolmen de Os Muiños (CARRERA RAMÍREZ, 2008) (imagen 6).

En algunos monumentos (Pedra Cuberta, Berdoias, Pedra da Arca, etc.) se han colocado algunas señales de orientación, sin acompañamiento de intervención alguna en el propio yacimiento, por lo que no los consideramos tratados. Tampoco podemos hacer referencia a actuaciones de conjunto sobre un grupo de monumentos tumulares cercanos, ya no necesariamente megalíticos ni decorados con arte parietal. Este tipo de proyectos tienen el atractivo añadido de la interrelación que se establece entre varios sitios, potenciando el interés sin necesidad de grandes intervenciones, incluso sobre simples túmulos no excavados (SILVA; FÉLIX, 1992). En muchos casos, a los valores culturales y arqueológicos se les suma un importante contenido paisajístico y natural, lo que hubiera justificado intervenciones como las de las sierras de Santa Mariña o del Barbanza, esta última fallida por falta de mantenimiento. En Portugal (Vila Nova de Paiva: CRUZ, 2000) podemos observar un buen ejemplo de este tipo de rutas, que incluye una amplia diversidad de monumentos (entre otros Juncais, Tanque, Picoto do Vasco) con niveles distintos de intervención. Intervenciones semejantes son las realizadas sobre monumentos en el área de Alcántara, Cáceres (BUENO RAMÍREZ et al., 1998 y 2000).

Según lo expuesto con anterioridad, no hay ninguna actuación que merezca ser reseñada y no se puede destacar ninguna por su especial calidad, está desde luego por debajo de los que merecen los monumentos. A la espera de lo que se realice en Dombate, la intervención reconstructiva de Chan de Castiñeiras 1 tiene a nuestro entender notables problemas conceptuales. Del resto sólo merece destacar la reciente ampliación de la finca y las dotaciones de Axeitos, a cargo de la Diputación de A Coruña (propietaria asimismo de Cabaleiros y Dombate). Si nos referimos a los cuidados que merecen los ortostatos con arte prehistórico, el análisis se vuelve bochornoso: se trata de la más antigua expresión artística hoy por hoy conocida en Galicia, que desaparece poco a poco ante la apatía general.

\section{IDEAS EN POSITIVO. LA GESTIÓN DE UN CONJUNTO DE YACIMIENTOS}

Para terminar con este escrito de una forma algo más optimista, nos gustaría hacer una escueta referencia a las posibles intervenciones en un área concreta y limitada, intentando ejemplificar lo que podría ser un modelo para un proyecto integral de conservación y exhibición del patrimonio megalítico de áreas geográficas más amplias. Para ello hemos elegido 
Tabla 2. Riesgo de alteración, valoración patrimonial, y propuesta de actuación para los monumentos estudiados en la Costa da Morte. Los valores de riesgo y valoración se establecen de 1 a 4 en sentido creciente

el muy notable conjunto de monumentos que se localizan en el territorio del occidente costero de la provincia de A Coruña coincidente a grandes rasgos con la Costa da Morte, y que abarca los ayuntamientos de Malpica, Ponteceso, Cabana, Laxe, Camariñas, Vimianzo, Zas, Muxía, Fisterra, Corcubión, Cée, Dumbría, Mazaricos y Carnota. En el estudio que repetidamente hemos citado (CARRERA RAMÍREZ, 2005) no se incluyó más que una muestra (tabla 2) del gran conjunto de monumentos conservado en esa zona. Aunque ubicado aquí, tampoco hemos incluido Dombate por tratarse de un yacimiento en pleno proceso de musealización y ajeno por tanto a la dinámica del resto.

Las primeras iniciativas de todo proceso de gestión de un conjunto patrimonial amplio es su valoración cuantitativa: por supuesto su catalogación, pero también la diagnosis de su estado y la estimación del riesgo de que prosiga la degradación. Estos elementos serán fundamentales para decidir la necesidad de acciones de protección directa que impidan el progreso de nuevas alteraciones. Así, en la tabla 2 encontramos monumentos (Pedra Moura, Pedra Cuberta) en un nivel de riesgo medio-alto (4 es el máximo) en los que deberían establecerse acciones preventivas urgentes. Paralelamente a lo anterior, debe establecerse una valoración cualitativa, en la que se estima el valor patrimonial de cada uno de los sitios considerados (de nuevo, 4 es el valor máximo). Según ese análisis, los monumentos más valiosos son Pedra Cuberta, Casa dos Mouros y Arca da Piosa. Los "mejores" monumentos son considerados no sólo por que poseen una valoración patrimonial elevada sino por mostrar un escaso riesgo de alteración, y sobre ellos se recomendará una actuación tendente a la exhibición pública. Hemos sido bastante restrictivos en las propuestas considerando la carestía de las mismas y la limitación de los recursos destinados al patrimonio arqueológico. El criterio fundamental ha sido la protección patrimonial con la mínima inversión posible. Evidentemente, toda esta información no predetermina el futuro del yacimiento, que será exhibido si existe voluntad y financiación suficiente ${ }^{2}$.

Con todo lo anterior, hemos establecido cinco tipologías de actuación sobre el conjunto de sitios. La complejidad de la propuesta se incrementa conforme lo hace la valoración patrimonial:

$\rightarrow$ Tapado con sedimentos. Es el tipo de acción sobre monumentos que no se van a exhibir, los de menor valoración patrimonial. Se trata del simple tapado con sedimentos ya sea de la totalidad del monumento, ya de las partes más sensibles (por poseer arte prehistórico, por ejemplo). En realidad los monumentos quedarán siempre parcialmente visibles (ortostatos, túmulo), por lo que esta propuesta no invalida su participación en acciones de exhibición más simples y de objetivos más amplios (rutas, etc.). En este grupo se incluyen algunos monumentos de alto valor patrimonial que se deciden tapar por el la importancia de las posibles accio-
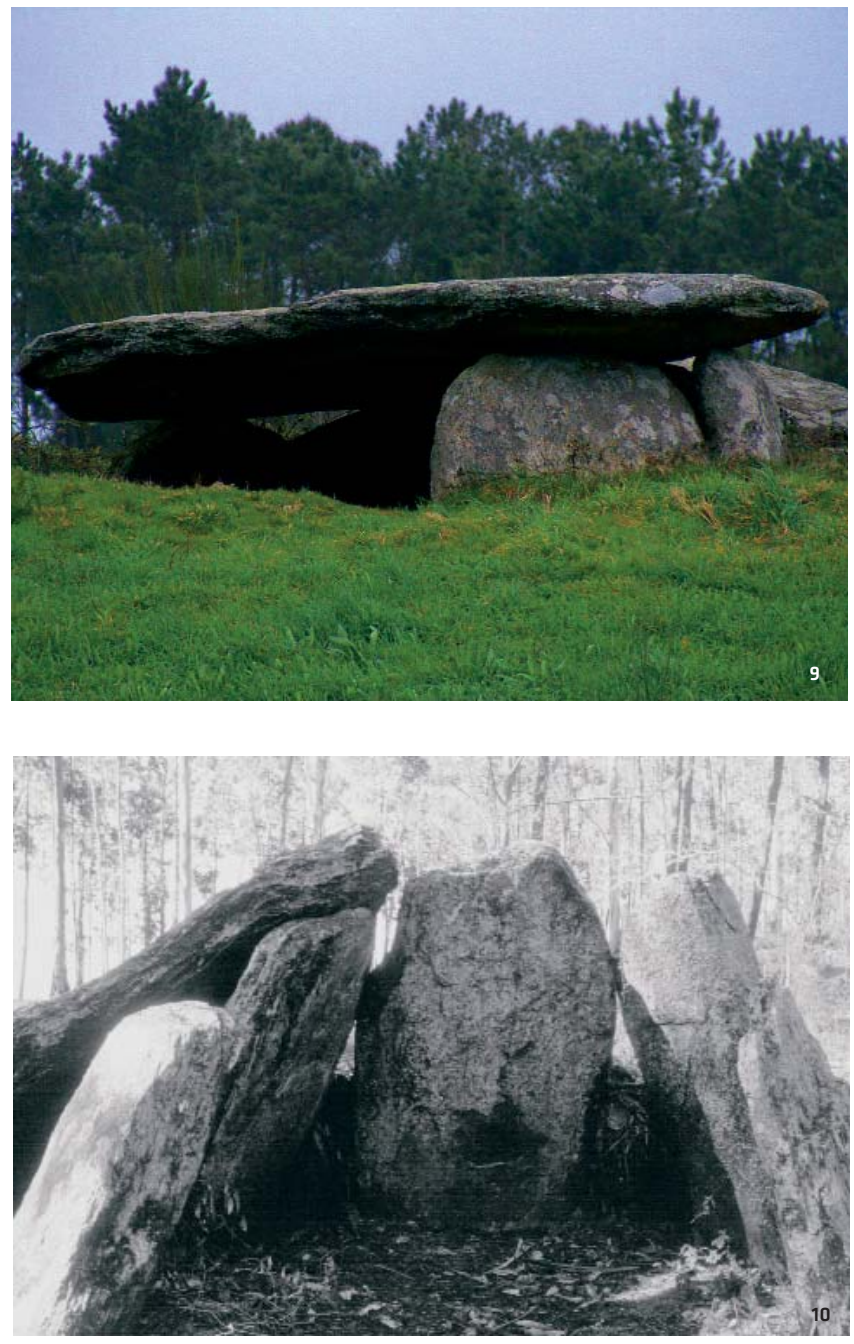

\begin{tabular}{llll}
$\begin{array}{llll}\text { TABLA } 2 \\
\text { MONUMENTo }\end{array}$ & $\begin{array}{l}\text { RIESG } \\
(\mathbf{1} \text { A 4) }\end{array}$ & $\begin{array}{l}\text { VALOR } \\
(\mathbf{1} \text { A 4) }\end{array}$ & ACCión PROPUESTA \\
\hline Pedra da Arca & 1,3 & 1,9 & Tapado con sedimentos \\
Pedra Moura (M. Carneo) & 2,8 & 2,2 & Tapado con sedimentos \\
Anta de Serramo & 1,2 & 1,6 & Tapado con sedimentos \\
Pedra Vixía & 1,2 & 1,3 & Tapado con sedimentos \\
Casa dos Mouros (C) & 2,5 & 2,5 & Exhibición sin obras \\
Arca da Piosa & 2,3 & 2,5 & Exhibición sin obras \\
Parxubeira & 2,1 & 2,2 & Exhibición sin obras \\
Casota de Berdoias & 1,4 & 2,0 & Exhibición sin obras \\
Fornela dos Mouros & 1,7 & 1,5 & Exhibición sin obras \\
Pedra Cuberta & 2,8 & 2,7 & Exhibición con obras
\end{tabular}



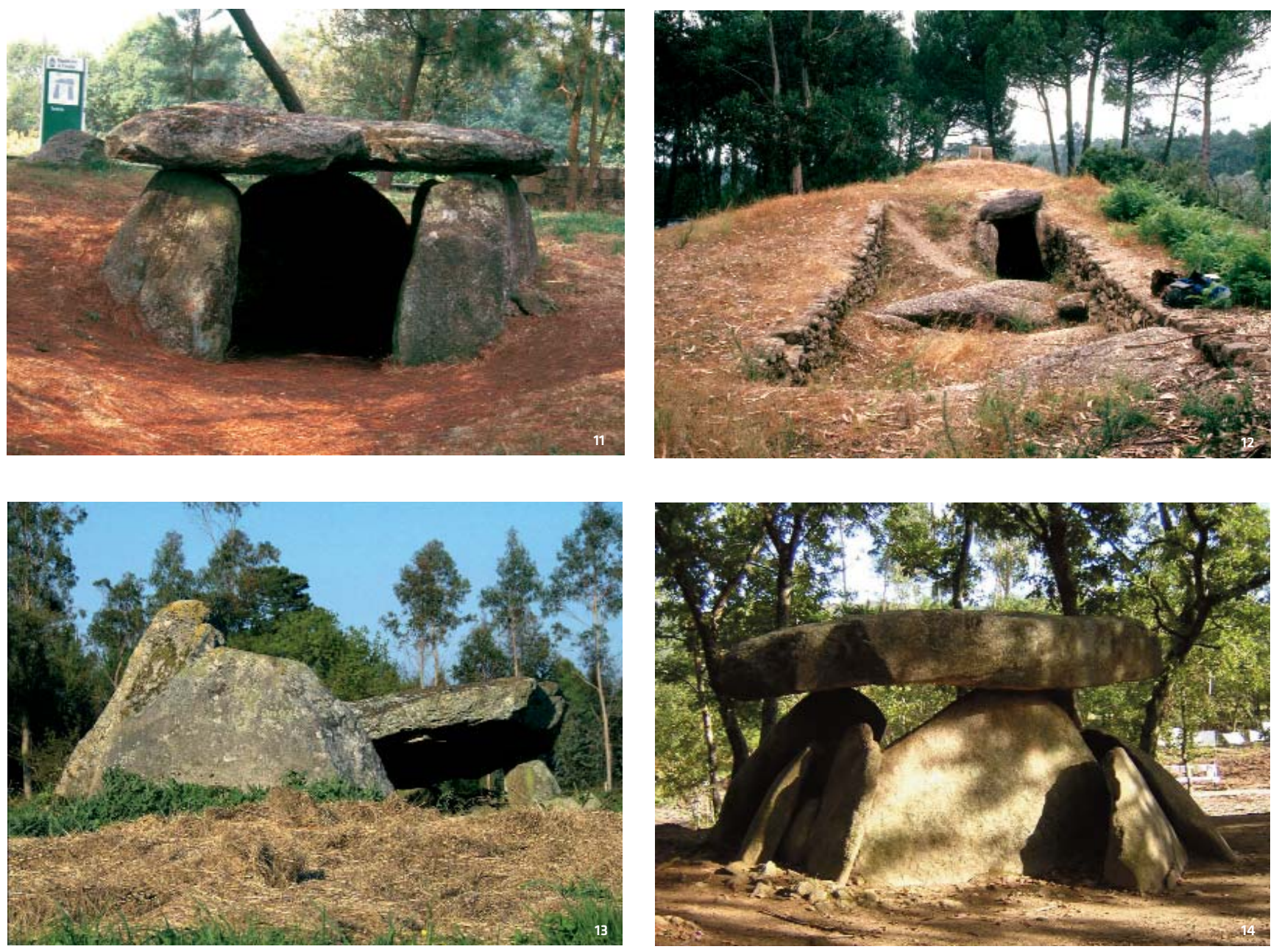

nes de excavación y/o exhibición necesarias (Pedra da Moura, Anta de Serramo) (imagen 7). También pertenecen a este grupo yacimientos relevantes con tímidos intentos de musealización (Pedra da Arca) cuyo pésimo estado de conservación recomienda un tapado urgente.

$\rightarrow$ Exhibición al aire libre sin obras. Se trata del grupo de menor valor patrimonial dentro de aquellos que se han señalado como exhibibles. Son yacimientos en muy diverso estado de conservación, desde algunos con tratamientos en un estado aceptable hasta aquellos francamente degradados que no poseen elementos de arte parietal (Fornela dos Mouros) o incluso carecen de túmulo (Casota de Berdoias). En todos ellos los tratamientos propuestos son de escasa entidad, y el recomendable incremento de las intervenciones en los más sobresalientes (Casa dos Mouros, Arca da Piosa) dependerá del interés social y administrativo. Las acciones son muy diversas, desde talas de árboles (Arca da Piosa) o roza de vegetación (Parxubeira, Casa dos Mouros), arreglos de caminos (Parxubeira), tratamientos simples de estabilización (Fornela dos Mouros) hasta tapados parciales de la pintura conservada (Arca da Piosa, Casa dos Mouros, Parxubeira). En algunos casos en la que la propiedad está muy diversificada (Casa dos Mouros), se recomienda encarecidamente la compra de los terrenos por parte de una administración pública.

$\rightarrow$ Exhibición al aire libre con obras. Se trata de monumentos con la suficiente entidad patrimonial como para recomendar su exhibición, aunque resulta necesaria la realización previa de algunas obras de mayor o menor entidad, muy diversas según el caso. Para la zona que estamos describiendo sólo ha sido incluido el monumento de Pedra Cuberta, donde sería necesaria la tala de los árboles que se asientan sobre el túmulo y una enérgica estabilización de la estructura (apuntalamiento de la cubierta del corredor). Al mismo tiempo, recomendamos el tapado del corredor con sedimentos, única forma de garantizar la conservación de la pintura conservada en éste. 
$\rightarrow$ Reconstrucción del yacimiento y/o túmulo, cubierta artificial. Aunque con criterios distintos, los últimos grados son acciones de musealización muy acusadas sobre monumentos muy notables y que poseen arte parietal. Puesto que se trata de proyectos de al to coste no hemos incluido ningún monumento en este grupo, aunque resulta evidente que los más relevantes desde el punto de vista patrimonial han quedado ya señalados y sería los que recomendásemos: Casa dos Mouros, Arca da Piosa, Pedra Cuberta y Parxubeira. Es la zona se integra el monumento de Dombate, en el que se está ejecutando una intervención de ese calibre.

A los tres últimos conjuntos debe sumarse una acción común en todos ellos: la mejora de la señalización, que incluya aspectos informativos de los que carecen la totalidad de los yacimientos visitados. Esta señalización podría ampliarse, en un nivel quizá inferior, a los monumentos no exhibidos, que sin embargo podrían configurar otro escalón expositivo relacionado con rutas y naturaleza, aspectos de los que hablábamos con anterioridad.

\section{Notas}

1 Se trata de visitas realizadas entre 1997 y 2003 a un conjunto amplio pero no definitivo de grandes monumentos. Es altamente probable que queden sin citar yacimientos con intervenciones más recientes o en zonas no visitadas por nosotros.

${ }^{2}$ Es bien conocido el interés de la administración autonómica en la creación de un parque arqueológico del megalitismo en esta zona. Su desenvolvimiento atraería sin duda recursos financieros más amplios y, por tanto, podrían ampliarse las modestas acciones ahora planteadas.

\section{Bibliografía}

APELLÁNIZ CASTROVIEJO, J.M.; FERNÁNDEZ MEDRANO, D.

(1978) El sepulcro de Galería segmentada de la Chabola de la Hechicera (Ervillar, Álava). Excavación y restauración. Estudios de Arqueología Alavesa, 9, pp.141-224

BELLO DIÉGUEZ, J.M.; CARRERA RAMÍREZ, F.; CEBRIÁN DEL MORAL, F. (1997) El proyecto de conservación del Dolmen de Dombate. Brigantium, 10, pp. 393-408

BUENO RAMÍREZ, P.; BALBÍN BEHRMANN, R.; BARROSO BERMEJO, R.; ALDECOA QUINTANA, A.; CASADO MATEOS, A.B. (1998) Dólmenes en la cuenca del Tajo: restauración y consolidación de megalitos en Alcántara (Cáceres). Trabajos de Prehistoria, 55 (1). pp. 171-183

BUENO RAMÍREZ, P.; BALBÍN BEHRMANN, R.; BARROSO BERMEJO, R.; ALDECOA QUINTANA, A.; CASADO MATEOS,

A.B. (2000) Dólmenes en Alcántara (Cáceres). Un proyecto de consolidación e información arqueológicas en las comarcas extremeñas del Tajo. Balance de las campañas de 1997 y 1998. Extremadura arqueológica, 8, pp. 129-168

CARRERA RAMíreZ, F. (coor.) (1 994). Memoria de los trabajos realizados en el Yacimiento Megalítico de Mota Grande (Verea, Ourense) [literatura gris] [Memoria inédita depositada en la Dir. Xeral do Patrimonio, Xunta de Galicia]
CARRERA RAMÍREZ, F. (2002) Sugerencias para la preservación del patrimonio megalítico. Minius, X, pp. 47-70

CARRERA RAMÍREZ, F. (2005) El arte parietal en monumentos megalíticos del Noroeste peninsular: dimensión del fenómeno y propuestas de conservación [literatura gris] [Tesis de Doctorado] Madrid: UNED, Dpto. de Prehistoria y Arqueología, 2005

CARRERA RAMÍREZ, F. (2008) El dolmen de Os Muiños (Agolada, Pontevedra). Intervención para la documentación y protección de la pintura megalítica conservada. Gallaecia, 27, pp. $113-135$

CARRERA RAMÍREZ, F. ; BARBI, V. (1 995). Protección e consolidación dos xacementos arqueolóxicos "O Forno dos Mouros" e "Os Castros" (Toques, A Coruña). En Arqueoloxía/Informes, 3, 1989. Santiago: Xunta de Galicia, 1995, pp. 211-213

\section{CARRERA RAMÍREZ, F. Y FÁBREGAS VALCARCE, R. (eds)} (2006), Arte Parietal Megalítico en el Noroeste Peninsular. Conocimiento y conservación. Santiago de Compostela: Tórculo Edicións, 2006

CASTRO, J.C,; VÁZQUEZ, S. (2007). La "Mámoa do Rey", rehabilltación de un yacimiento tumular en el marco de su puesta en valor (Chan de Castiñeiras-Vilaboa-Pontevedra). En:' IV Congreso Internacional sobre Musealización de Yacimientos Arqueológicos. Santiago de Compostela: Consellería de Cultura e Deporte, 2007
CRUZ, D.J. (coor.) (2000). Roteiro Arqueológico de Vila Nova de Paiva. Vila Nova de Paiva: Cámara Municipal, 2000

EGUILETA FRANCO, J.M. (1 999). A Baixa Limia galega na Prehistoria Recente. Arqueoloxía dunha paisaxe na Galicia interior. Ourense: Excma. Deputación Provincial de Ourense, 1999

FUENTE ANDRÉS, F. (1 988). La conservación del megalitismo: un caso de consolidación. En Actas VI Congreso de Conservación de Bienes Culturales (6. 1986. Tarragona). Barcelona: Generalitat de Catalunya, 1988, pp. 361-368

RODRÍGUEZ CASAL, A. (1989) La necrópolis megalítica de Par xubeira. A Coruña : Museu Arqueolóxico Provincial, 1989

SILVA, M.F.M.; FÉLIX, P.J.S. (1992) Campanha de limpeza, protecçao, cartografia e sinalizaçao do núcleo megalítico de Châ de Lamas. Cadernos Arqueología e Patrimonio, 1992, pp. 17-25

SOBRINO BUHIGAS, R. (1956) Excavación de una sepultura megalítica en Moaña, Península del Morrazo (Pontevedra). Noticiario Arqueológico Hispánico, 3-4. pp. 27-36

STOCKLER, C.C. (1996) Os Monumentos con "tumulus" da Serra da Aboboreira. Dissertaçao de Mestrado em Arqueología [literatura gris] [presentación en Facultade de Letras da Universidade do Porto] 